\title{
Do aeration conditions affect arsenic and phosphate accumulation and phosphate transporter expression in rice (Oryza sativa L.)?
}

by Wu, C., Wang, Q., Xue, S., Pan, W., Lou, L., Li,D. and Hartley, W.

Copyright, Publisher and Additional Information: This is the author accepted manuscript. The final published version (version of record) is available online via Springer Please refer to any applicable terms of use of the publisher.

DOI: $10.1007 / \mathrm{s} 11356-016-7976-3$

Harper Adams

University

Wu, C., Wang, Q., Xue, S., Pan, W., Lou, L., Li,D. and Hartley, W. 2016. Do aeration conditions affect arsenic and phosphate accumulation and phosphate transporter expression in rice (Oryza sativa L.)? Environmental Science and Pollution Research.

31 October 2016 
Does aeration conditions affect arsenic and phosphate accumulation and phosphate transporter expression in rice (Oryza sativa L.)?

\section{Chuan WU, \#, Qiongli Wang, Shengguo XUE ${ }^{a}$, Weisong PAN ${ }^{b}$, \#, Laiqing Lou, Daojun Li, William HARTLEY}

${ }^{a}$ School of Metallurgy and Environment, Central South University, Changsha 410083, China.

E-mail:wuchuan@csu.edu.cn

${ }^{\mathrm{b}}$ College of Bioscience and Biotechnology, Hunan Agricultural University, Changsha 410128, China

${ }^{c}$ College of Life SciencesNanjing Agricultural UniversityNanjingPeople's Republic of China

${ }^{\mathrm{d}}$ Crop and Environment Sciences Department, Harper Adams University, Newport, Shropshire, TF10

8NB, United Kingdom

* Corresponding author:

Tel: +86-13787148441. Fax: +86-731-85552958. E-mail address: sgxue@csu.edu.cn.

${ }^{\#}$ These authors contributed equally to the manuscript 


\section{Abstract}

Widespread contamination of rice with arsenic (As) has revealed a major exposure pathway to humans. The present study aimed to investigate the effects of oxygen in the rhizosphere on phosphate transporter (for arsenate transportation) expressions in four rice genotypes, on As and phosphate accumulation and As speciation. Oxygenation marginally increased root and shoot length. Total As concentrations in rice roots were dramatically reduced following oxygenation compared to stagnant treatments $(p<0.001)$. Oxygenated treatments significantly increased arsenate whilst reducing arsenite concentrations in roots $(p<0.001)$. Root arsenite concentrations were 1.5-2.5 times greater in stagnant than in oxygenated treatments. Total $\mathrm{P}$ concentrations in rice roots were dramatically increased following aeration compared to stagnant treatments. The relative abundance of phosphate transporter (inorganic phosphate transporter and phosphate: $\mathrm{H}^{+}$symporter family protein) expressions showed down-regulation in stagnant treatments, particularly for SY-9586, XWX-17, XWX-12 in inorganic phosphate transporter expressions, and XWX-17 in phosphate: $\mathrm{H}^{+}$symporter family protein expression $(p<0.05)$. The relative abundance of phosphate carrier protein expressions were relatively higher than the other phosphate transporters, showing up-regulation in stagnant treatments.

Keywords: Arsenic; Rice; Phosphate; Phosphate transporter 


\section{Introduction}

Arsenic (As) is an environmental contaminant and well documented as a human carcinogen (Zhu et al., 2008E; Wu et al., 2015). Exposure from drinking As-contaminated groundwater has caused thousands of people to develop arsenicosis in parts of Southeast Asia (Meharg et al., 2003; Perry et al., 2011) whilst widespread As contamination of rice and other crops has provided a major exposure pathway to humans via the food chain (EFSA., 2009; Meharg et al., 2003, 2009 ). Elevated As concentrations in paddy soils has originated from both geological and anthropogenic activities, the latter being the major contributor due to smelting, mining and irrigation using As-contaminated groundwater (Liao et al., 2005; Jia et al., 2014). Due to its inherent physiological characteristics and preference to anaerobic conditions rice is particularly efficient at As uptake and accumulation compared to other crops (Su et al., 2010; Wu et al., 2016). Rice is a staple food consumed by half the world's population, and as an export commodity, rice consumption has posed an increasing threat to human health globally due to contamination by As (Stone et al., 2006; Seyfferth et al., 2014).

Arsenic in rice plants can exist both as inorganic and organic species. Inorganic species, As(V) and As(III), present greater toxicity and bioavailability than organic As (Qu et al., 2014; Wu et al., 2015). Therefore, total As concentration and As speciation should both be taken into consideration for health risk assessment (Novoa et al., 2007; Qu et al., 2014). Arsenic speciation will dictate the uptake pathway into rice (Zhao et al., 2010; Wu et al., 2016). For example, studies have shown that As(III) is taken up through silicic acid transport systems (Ma et al., 2008), whilst $\mathrm{As}(\mathrm{V})$, a chemical analog of phosphate, shares the same transporters with phosphate (Meharg and Hartley-Whitaker, 2002; Liu et al., 2004). Abedin et al (2002) revealed that phosphate strongly suppressed $\mathrm{As}(\mathrm{V})$ uptake in rice plants. $\mathrm{Hu}$ et al (2005) reported that $\mathrm{P}$ fertilizer significantly reduced As accumulation in rice roots whilst $\mathrm{Wu}$ et al (2015) showed that $\mathrm{P}$ addition increased As concentrations in rice shoots. Arsenate is the 
predominant As species in aerobic soils and will compete with $\mathrm{P}$ for absorption sites and uptake transporters in rice roots (Jiang et al., 2014).

Recent studies have reported that water management has profound influences on As uptake and accumulation in rice plants (Xu et al., 2008; Li et al., 2009; Somenahally et al., 2011; Norton et al., 2013). Takahashi et al (2004) found that As was sequestered on Fe(hydr)oxides when soils were not flooded, but upon flooding, was released into the soil solution due to reductive dissolution of the Fe (hydr)oxides and reduction of $\mathrm{As}(\mathrm{V})$ to $\mathrm{As}(\mathrm{III})$. Xu et al (2008) reported that aerobic conditions greatly reduced As bioavailability, subsequently reducing As accumulation in rice plants; aerobic conditions reduced the concentration of inorganic As by 2.6-2.9 fold in rice grain compared to flooded treatments, which was in accordance with Norton et al (2013). Li et al (2009) also showed that growing rice aerobically reduced As in rice plants. A field-scale experiment conducted by Somenahally et al (2011) demonstrated that intermittent flooding significantly reduced total As concentrations in the rhizosphere and grain compared to continually flooded conditions.

The objectives of the present work were to evaluate (1), the effects of root aeration on the acquisition of $\mathrm{P}$ and biomass production of rice, (2) investigate the changes of Pi transporters (OsPT2, 6 and 11) in rice plants, and (3) investigate the effects of root aeration on the accumulation and transformation of arsenate in rice plants.

\section{Materials and Methods}

\subsection{Rice seedlings}

Two hybrid subspecies Xiangfengyou9 ('XFY-9’), Shenyou9586 ('SY-9586’) and two indica subspecies Xiangwanxian17 ('XWX-17') and Xiangwanxian12 ('XWX-12'), with radial oxygen losses of 9.55, 10.83, 19.7 and $27.0 \mu \mathrm{mol} \mathrm{O} \mathrm{g}^{-1}$ root dry weight $\mathrm{h}^{-1}$ respectively, were chosen for the investigations (Wu et al., 2015). Seeds were obtained from Hunan Agricultural University. The seeds were 
germinated in culture dishes on moist filter papers after first being surface sterilized with a $30 \% \mathrm{H}_{2} \mathrm{O}_{2}$ for 15 min. Seeds were then subsequently thoroughly washed with deionized water three times. Germinated rice seedlings were then grown in Kimura B nutrient solution for 2 weeks (Ma et al., 2001).

\subsection{Aeration and Arsenate Treatments}

After 2 weeks growth in the nutrient solution, uniform seedlings (approximately $20 \mathrm{~cm}$ ) were selected and transplanted into 10-liter plastic vessels (four vessels, twelve plants per vessel) with Kimura B nutrient solution. Initially the nutrient solutions were bubbled with $\mathrm{N}_{2}$ gas for $24 \mathrm{~h}$ to deoxygenate them before use. The deoxygenated nutrient solution contained $0.1 \%$ w/v agar, which more closely resembles stagnant conditions of flooded paddy field soil than $\mathrm{N}_{2}$-flushed solutions alone; dilute agar prevents convective movement within the solution (Wu et al., 2012). The $\mathrm{pH}$ of the nutrient solution was maintained with $\mathrm{KOH}$ or $\mathrm{HCl}$ at approximately 5.8 , with the solution renewed once every 5 days. Vessels were placed randomly in a greenhouse (maintained at $25^{\circ} \mathrm{C}$ during the day and $20^{\circ} \mathrm{C}$ at night, with $70 \%$ relative humidity) and natural light was supplemented with sodium light (1200 Lux, a

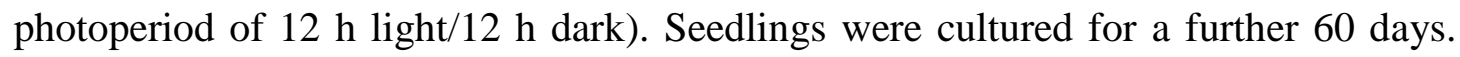
Plants were then transplanted to 2-liter plastic vessels (four plants per vessel) containing Kimura B nutrient solution, with either no arsenic (control) or $4 \mu \mathrm{M}$ arsenate $\left(\mathrm{Na}_{2} \mathrm{HAsO}_{4}\right)$. Half the plants were aerated using an air pump for the entire growth period, while the other half were treated as stagnant as previously described. 
Treatments were designated as Stagnant -As (stagnant with no As), Aeration -As (aerated with no As), Stagnant +As (stagnant with arsenate) and Aeration +As (aerated with arsenate). There were three replicates per treatment, with four plants per replicate (vessel). The nutrient solution was renewed every 2 days, and vessels were randomly arranged in the greenhouse and plants were cultured for 10 days.

\subsection{Plant Analysis for Total As and $P$}

Plants were harvested after 10 days, carefully washed using deionized water, and then divided into roots and shoots. Root length, shoot length and fresh root weight were measured. Then $0.5 \mathrm{~g}$ fresh root was collected for RNA extraction. The remaining root and shoot samples were divided equally, and either oven-dried at $70^{\circ} \mathrm{C}$ to a constant weight for total As determination, or freeze-dried and stored at $-20^{\circ} \mathrm{C}$ prior to total $\mathrm{P}$ and As species determination.

For total As determination, $0.5 \mathrm{~g}$ sample was weighed into a conical flask (100 $\mathrm{ml}$ ), and $5 \mathrm{ml}$ concentrated nitric acid added. The samples were left to digest overnight at room temperature $\left(25^{\circ} \mathrm{C}\right)$, then placed on an electric hot plate $\left(120^{\circ} \mathrm{C}\right)$, until the solution became clear. After digestion, samples were filtered and diluted to $20 \mathrm{ml}$ with deionized water into colorimetric tubes (Wu et al., 2015, 2016). The total As concentration (root and shoot) was determined using HG-AFS (AFS-8230, Beijing Jitian Instruments Co., China) (Shi et al., 2013; Wu et al., 2015). A certified reference material (bush branches and leaves, GBW07603) was used and As recovery ranged from $85.5 \%$ to $93.5 \%(n=3)$. 
To determine the $\mathrm{P}$ concentration, freeze-dried root and shoot samples were mixed and ground using a mill. $0.1 \mathrm{~g}$ and $0.5 \mathrm{~g}$ sub-samples of roots and shoots were weighed respectively, and digested using $5 \mathrm{ml}$ concentrated sulfuric acid in a $50 \mathrm{ml}$ glass tube on a heating block at $100{ }^{\circ} \mathrm{C}$ for $20 \mathrm{~min}$. Tubes were then subsequently placed on a heating block at $380{ }^{\circ} \mathrm{C}$ for $2 \mathrm{~h}$. Each digest was diluted, filtered and made to volume $(25 \mathrm{ml})$ with deionized water. Total $\mathrm{P}$ in digests was determined using molybdenum blue method (Chen et al., 2013) using a spectrophotometer (UV-1601, Shimadzu, Japan) at a wavelength of $882 \mathrm{~nm}$. A certified reference material (bush branches and leaves, GBW07603) was used and P recovery ranged from $93 \%$ to $98 \%(n=3)$.

\subsection{Plant Analysis for As Speciation}

For determination of As species, samples were ground with liquid $\mathrm{N}_{2}$ to ensure stabilization (Shi et al., 2013; Wu et al., 2015). Milled rice grain (1.0 g) was added to centrifuge tubes $(50 \mathrm{ml})$, and $20 \mathrm{ml}$ nitric acid (1\%) added. The samples were then heated to $95^{\circ} \mathrm{C}$ for $1.5 \mathrm{~h}$. After the samples had cooled to room temperature $\left(25^{\circ} \mathrm{C}\right)$, the extracting solution was centrifuged at $5000 \mathrm{r} / \mathrm{min}$ for $10 \mathrm{~min}$ and the supernatant filtered $(0.22 \mu \mathrm{m})$. Arsenic speciation was determined using HPLC-HG-AFS (HPLC, Shimadzu LC-15C Suzhou Instruments Co., China; HG-AFS, AFS-8230, Beijing Jitian Instruments Co., China) (Shi et al., 2013; Wu et al., 2016). 


\subsection{RNA Isolation and RT-PCR}

The total RNA was extracted from roots using an RNA extraction kit (RNeasy Plant Mini Kit, Qiagen, Germany). Total RNA (500 ng) was used for first-strand cDNA synthesis using SuperScript III Reverse Transcriptase (Invitrogen, USA). One-tenth of the reaction volume was used as the template for phosphate transporters (inorganic phosphate transporter, phosphate carrier protein and phosphate: $\mathrm{H}^{+}$ symporter family protein) (Li et al., 2010) and actin (internal control) amplification using PowerUp SYBR Green Master Mix (Life Technologies, USA) for real-time polymerase chain reaction. The three phosphate transporters were selected as they were reported for potential phosphate transportation in indica rice genotypes ( $\mathrm{Li}$ et al., 2010).

The primer sequences of the different genes were as follows:

inorganic phosphate transporter, 5'-GTACCACCACTGGACGAC-3' (forward) and 5'-AAGTTGGCGAAGAAGAAGG-3' (reverse) (Li et al., 2010);

phosphate carrier protein, 5'-GCGTCAGATTCCTTATACTATG-3' (forward) and 5'-GGATGAGATGCTTGTATGC-3' (reverse);

phosphate: $\mathrm{H}^{+}$symporter family protein, 5'-ACCACTGGACAACGAAAG-3'

(forward) and 5'-CGAAGTTGGCGAAGAAGA-3' (reverse) (Li et al., 2010);

Actin, 5'- GACTCTGGTGATGGTGTCAGC-3' (forward) and 5'-GGCTGGAAGAGGACCTCAGG-3' (reverse).

qRT-PCR was carried out in a StepOnePlus instrument (Applied Biosystems, USA) and relative expression normalized against Actin using the comparative CT method recommended by the instrument manufacturer. Experiments were repeated 
at least three times for statistical analysis of each individual experimental set. All values in the experiments were expressed as mean \pm SD.

\subsection{Data Analysis}

All data was analyzed in SPSS 23.0. Figures were created in Origin 9.0.

\section{Results and Discussion}

\subsection{Plant growth}

Plant growth parameters root length, root weight and shoot length were measured (Figure 1). There were significant genotypic effects on root length $(P<0.001)$, root weight $(P<0.001)$ and shoot length $(P<0.001)$ of rice plants. The longest root length, $28.5 \mathrm{~cm}$, was from genotype XFY-9 in Stagnant+As treatments, whilst the shortest, $19.8 \mathrm{~cm}$, was from genotype XWX-17 with Stagnant+As treatments. With the exception of genotype XWX-17 in +As treatments $(p<0.05)$, root length was not significantly affected by different aeration treatments. In addition, aeration had significant effects on root length in genotype XWX-12 $(p<0.05)$ in both control and As treatments. Root weight was greatest for genotype XFY-9 in Stagnant+As treatments and lowest in genotype XWX-17 in Aeration-As treatments respectively (Figure 1). Additionally, there were no significant differences between control and +As treatments on root and shoot length and root weight $(p>0.05)$. Root and shoot length and fresh root weight were significantly different between different genotypes, which is in agreement with previous studies (Wu et al., 2015, 2016). However, +As 
treatments did not exert any significant difference in root and shoot length and root weight, which was different to other studies (Marin et al., 1993; Abedin et al., 2002b). In other investigations, addition of arsenate had not revealed any significant reductions (Marin et al., 1993; Carbonell et al., 1998; Wu et al., 2015), possibly due to different growing conditions and genotypes. In addition, root length was slightly enhanced by aerated treatments compared with stagnant treatments, which is in agreement with other studies (Comis, 1997; Wu et al., 2012).

\subsection{Arsenic accumulation and speciation}

Arsenic was undetectable in plants grown in As-free treatments (Figure 2). There were significant genotypic effects on total As concentrations in rice roots $(P<0.001)$ and shoots $(P<0.001)$ with the same treatments. The hybrid genotypes $($ SY-9586 and XFY-9), with lower ROL, accumulated slightly greater As concentrations in roots than indica genotypes (XWX-12 and XWX-17). Total As concentrations in rice roots were dramatically reduced following aeration, (82.4 to $230.9 \mathrm{mg} / \mathrm{kg}$ ), compared to stagnant treatments $(198.4$ to $265.9 \mathrm{mg} / \mathrm{kg})(P<0.001)$. In addition, there were no significant differences in total As concentrations of rice shoots between aeration and stagnant treatments, although aeration slightly reduced total As concentrations in shoots compared to stagnant treatments.

Methylated As species (MMA and DMA) were not detectable in rice roots or shoots in different treatments (Table 1 and 2). Arsenite was the predominant As species in roots, accounting for $39 \%$ to $88 \%$ of extractable As (the sum of all As species), 
except for genotype XWX-12 grown with aeration +As. Arsenate concentrations were undetectable in shoots, with only arsenite detected, even in arsenate treatments. Results indicated that there were genotypic differences in arsenite accumulation in roots and shoots, with hybrid genotypes (SY-9586 and XFY-9) accumulating greater arsenite concentrations in shoots than indica genotypes (XWX-12 and XWX-17). Compared to stagnant treatments, aerated treatments significantly increased arsenate concentrations, but reduced arsenite concentrations in roots $(\mathrm{p}<0.001)$. In As treatments, root arsenite concentrations in stagnant treatments were 1.5-2.5-fold greater than that in aerated treatments (Table 1). Genotype XFY-9 in Stagnant+As treatments contained greater arsenite concentrations $(165 \mathrm{mg} / \mathrm{kg})$, whilst genotype XWX-12 in Aeration+As treatments contained the lowest arsenite concentrations $(30.1 \mathrm{mg} / \mathrm{kg})$. In addition, arsenite concentrations in shoots from stagnant treatments were greater than that from aerated treatments (Table 2). Arsenite concentrations ranged from 7.03 to $36.7 \mathrm{mg} / \mathrm{kg}$ in shoots, with the lowest value found in genotype XWX-12 (Aeration +As) and the greatest in genotype XWX-17 (Stagnant +As).

Root and shoot total As were significantly different between different genotypes, with hybrid genotypes, with lower ROL, accumulating greater As than indica genotypes, which is in agreement with previous pot studies (Wu et al., 2015). However, the differences were not significant, which may due to the increased iron plaque formation in pot experiments sequestering more As on the plaque, and reducing As transportation to rice roots (Wu et al., 2016). Root As concentrations in aerated treatments were significantly lower than stagnant treatments (Figure 2). Arao 
et al. (2009) revealed that flooding increased As in rice straw and grains compared with aerobic conditions. Norton et al. (2013) also showed that aerobic conditions may decrease grain As content compared with flooded conditions. Furthermore, $\mathrm{Hu}$ et al. (2015) showed that rice growing in aerobic conditions resulted in 3-16 times lower As accumulations than in flooded conditions.

The dynamics of As speciation under both flooded and aerobic conditions, as well as As accumulation in rice shoots and grains were investigated by $\mathrm{Xu}$ et al., (2008); it was observed that As concentrations in the soil solution were 4-16 times greater under flooded conditions, while grain As was 10-15 times greater than the aerobically grown rice. Flooding may reduce redox potential, causing As desorption from soil particles, which greatly increases As bioavailability in both greenhouse $(\mathrm{Xu}$ et al., 2008; Hartley et al., 2010) and field studies (Takahashi et al., 2004). In the present hydroponic experiments, decreased As accumulation in aerated treatments may be due to less As transported into rice roots.

The present study demonstrated that arsenite and arsenate were both lower in rice roots and shoots from aerated compared to stagnant conditions (Table 1, 2), especially for root iAs in genotypes XFY-9, XWX-17 and XWX-12, and shoot iAs in SY-9586. Arao et al. (2009) also found that the concentration of inorganic As was 2.6-2.9 times greater in grain from flooded treatments than in those from aerobic treatments. In addition, organic As species were undetectable in both roots and shoots, which is in agreement with other studies (Chen et al., 2012; Wu et al., 2012). 


\subsection{Phosphate accumulation and transporter expression}

Phosphate concentrations in rice roots (a) and shoots (b) are shown in Figure 3. The hybrid genotypes (SY-9586 and XFY-9), with lower ROL, accumulated slightly lower P concentrations in roots and shoots than indica genotypes (XWX-12 and $\mathrm{XWX}-17)$. Total $\mathrm{P}$ concentrations in rice roots were dramatically increased following aeration, (960 to $1616 \mathrm{mg} / \mathrm{kg}$ ), compared to stagnant treatments (834 to $1188 \mathrm{mg} / \mathrm{kg}$ ), especially in control and As treatments of genotype SY-9586, in +As of genotype XWX-17 and in controls of genotype XWX-12. In addition, total P concentrations of rice shoots were slightly higher in aerated treatments, especially in + As of genotype SY-9586 and genotype XWX-12 in controls.

The relative abundance of phosphate transporter (inorganic phosphate transporter and phosphate: $\mathrm{H}^{+}$symporter family protein) expressions presented a down-regulation trend in stagnant treatments compared to those that were aerated; being significantly different for SY-9586, XWX-17, XWX-12 in inorganic phosphate transporter expressions, and XWX-17 in phosphate: $\mathrm{H}^{+}$symporter family protein expression $(P<0.05)$ (Figure 4$)$. However, The relative abundance of phosphate carrier protein expressions were relatively higher than the other two phosphate transporters, and presented an up-regulated trend in stagnant treatments, especially in XFY-9 $(p<0.05)$. Furthermore, there were no significant genotypic differences with phosphate transporter expressions, regardless of hybrid or conventional indica genotypes. 
Arsenate and phosphate (P) share the same transporters in plants (Chen et al., 2013). The inorganic phosphate transporter, phosphate carrier protein and phosphate: $\mathrm{H}^{+}$ symporter family protein were selected in this investigation as their expressions were up-regulated with low $\mathrm{P}$ stress in indica rice roots, which show potential for $\mathrm{P}$ transportation in indica rice ( $\mathrm{Li}$ et al., 20010). In the present study, the inorganic phosphate transporter and phosphate: $\mathrm{H}^{+}$symporter family protein expressions were significantly reduced by aeration, leading to a reduction in As accumulation in roots (Figure 4). However, phosphate carrier protein expressions were significantly increased by aeration, stimulating improved root length (Figure 1) and significantly enhancing $\mathrm{P}$ accumulation in roots and shoots (Figure 3). The reduced accumulation of total As and arsenite may be due to reduced inorganic phosphate transporter and phosphate: $\mathrm{H}^{+}$symporter family protein expressions, or as a result of competition from $\mathrm{P}$ and As for the phosphate carrier protein transporter. Chen et al. (2013) also found that the reduced expression of Pi transporters led to reduced arsenate concentrations in plant tissues. Chen et al. (2013) found that with the colonization of arbuscular mycorrhizal fungi (AMF), Phosphate transporter OsPT11 increased whereas OsPT2 decreased significantly. The increased expression of OsPT11 was one of the most important factors that led to the significantly higher $\mathrm{P}$ concentration in rice tissues, which compensated for the down-regulation of OsPT2. What is more, Rausch et al. (2001) found that StPT1 and StPT2 mRNA levels in potato were reduced and StPT3 was significantly induced in cells containing arbuscules. In barley (Hordeum vulgare) under AMF colonization, HvPht1;1 and HvPht1;2 genes were 
down-regulated while HvPht1;8 was up-regulated and led to lower As uptake and higher P/As molar ratio (Christophersen et al., 2009).

\section{Conclusion}

The present study aimed to investigate the effects of rhizosphere aeration on phosphate transporter (for arsenate transportation) expressions, and on arsenic accumulation and speciation in two hybrid rice genotypes and two conventional indica genotypes. Aeration marginally increased root length, particularly in genotypes XWX-17 and XWX-12 from both control and As treatments. Total As concentrations in roots were dramatically reduced following aeration compared to stagnant treatments. In addition, there were no significant differences in total As concentrations in shoots between aerated and stagnant treatments, although aeration slightly reduced total As concentrations in shoots. Aerated treatments significantly increased arsenate, whilst reducing arsenite concentrations in roots. Root arsenite concentrations in stagnant treatments were 1.5-2.5-fold greater than in aerated treatments. Total $\mathrm{P}$ concentrations in roots were dramatically increased following aeration compared to stagnant treatments, especially in genotype SY-9586 from both control and As treatments, in genotype XWX-17 with +As and in genotype XWX-12 in control treatments. In addition, total $\mathrm{P}$ concentrations of shoots were slightly greater in aerated treatments, especially in genotype SY-9586 grown in +As treatments, and in genotype XWX-12 in control treatments. The relative abundance of phosphate transporter expressions also presented a down-regulation trend in 
stagnant treatments, especially for SY-9586, XWX-17 and XWX-12 in inorganic phosphate transporter expressions, and XWX-17 in phosphate: $\mathrm{H}^{+}$symporter family protein expression. However, the relative abundance of phosphate carrier protein expressions were relatively higher than the other two phosphate transporters, and presented an up-regulated trend in stagnant treatments. There were also no significant genotypic differences with phosphate transporter expressions, regardless of hybrid or conventional indica genotypes.

\section{Acknowledgements}

Financial support from the National Natural Science Foundation of China (No. $41201493 ; 31300815)$ is gratefully acknowledged.

\section{Reference}

Christophersen, H.M., Smith, F.A., Smith, S.E., 2009. Arbuscular mycorrhizal colonization reduces arsenate uptake in barley via downregulation of transporters in the direct epidermal phosphate uptake pathway. New Phytologist 184, 962-974.

Rausch, C., Daram, P., Brunner, S., Jansa, J., Laloi, M., Leggewie, G., Amrhein, N., Bucher, M., 2001. A phosphate transporter expressed in arbuscule-containing cells in potato. Nature $414,462-470$.

Wu C, Zou Q, Xue SG, Mo JY, Pan WS, Lou LQ, Wong MH. 2015. Effects of silicon ( $\mathrm{Si}$ ) on arsenic (as) accumulation and speciation in rice (Oryza sativa L.) genotypes with different radial oxygen loss (ROL). Chemosphere 138, 447-453.

Wu C, Zou Q, Xue SG, Pan WS, Huang L, Hartley W, Mo JY, Wong MH. 2016. The effect of silicon on iron plaque formation and arsenic accumulation in rice 
genotypes with different radial oxygen loss (ROL). Environment Pollution 212, 27-33.

Wu, C., Ye, Z.H., Shu, W.S., Zhu, Y.G., Wong, M.H., 2011. Arsenic accumulation and speciation in rice are affected by root aeration and variation of genotypes. J. Exp. Bot. 62 (8), 2889-2898.

Arao T, Kawasaki A, Baba K, Mori S, Matsumoto S. 2009. Effects of water management on cadmium and arsenic accumulation and dimethylarsinic acid concentrations in japanese rice. Environmental Science \& Technology 43, 9361-9367. Norton GJ, Adomako EE, Deacon CM, Carey A, Price AH, Meharg AA. 2013. Effect of organic matter amendment, arsenic amendment and water management regime on rice grain arsenic species. Environmental Pollution 177, 38-47.

Hu P, Ouyang Y, Wu L, Shen L, Luo Y, Christie P. 2015. Effects of water management on arsenic and cadmium speciation and accumulation in an upland rice cultivar. Journal of Environment Science (China) 27, 225-231.

Xu XY, McGrath SP, Meharg AA, Zhao FJ. 2008. Growing rice aerobically markedly decreases arsenic accumulation. Environmental Science \& Technology 42, 5574-5579.

Hartley W, Wu C, Dickinson NM, Riby P, Lepp NW, Wong MH. 2010. Arsenic mobility and bioavailability in flooded industrially polluted UK soils. Land Contamination \& Reclamation 18, 267-278.

Takahashi Y, Minamikawa R, Hattori KH, Kurishima K, Kihou N, Yuita K. 2004. Arsenic behavior in paddy fields during the cycle of flooded and non-flooded periods. Environmental Science \& Technology 38, 1038-1044.

Chen XW, Wu FY, Li H, Chan WF, Wu C, Wu SC, Wong MH. 2013. Phosphate transporters expression in rice (Oryza sativa L.) associated with arbuscular mycorrhizal fungi (AMF) colonization under different levels of arsenate stress. Environmental \& Experimental Botany 87, 92-99.

Zhu Y, Williams PN, Meharg AA 2008. Exposure to inorganic arsenic from rice: A global health issue?In. 169-171. 
Wu C, Zou Q, Xue S, Mo J, Pan W, Lou L, Wong MH 2015. Effects of silicon (Si) on arsenic (as) accumulation and speciation in rice (Oryza sativa L.) genotypes with different radial oxygen loss (ROL).In. 447-453.

Meharg, A. A.; Rahman, M. Arsenic contamination of Bangladesh paddy field soils: implications for rice contribution to arsenic consumption. Environ. Sci. Technol. 2003, $37,229-234$.

(10) Perry, M. R.; Wyllie, S.; Prajapati, V. K.; Feldmann, J.; Sundar, S.; Boelaert, M.; Fairlamb, A. H. Visceral leishmaniasis and arsenic: an ancient poison contributing to antimonial treatment failure in the Indian subcontinent? PLoS Negl. Trop. Dis. 2011, 5, No. e1227.

76. Meharg AA, Williams PN, Adomako E, Lawgali YY, Deacon C, et al. 2009. Geographical variation in total and inorganic arsenic content of polished (white) rice. Environ. Sci. Technol. 43:1612-17

(3) Su, Y. H.; McGrath, S. P.; Zhao, F. J. Rice is more efficient in arsenite uptake and translocation than wheat and barley. Plant Soil 2010, 328 (1-2), 27-34.

(1) European Food Safety Authority (EFSA).. Scientific opinion on arsenic in food. EFSA Panel on Contaminants in the Food Chain (CONTAM). EFSA J. 2009, 7, $1531-1550$.

(6) Liao, X. Y.; Chen, T. B.; Xie, H.; Liu, Y. R. Soil As contamination and its risk assessment in areas near the industrial districts of Chenzhou City, Southern China. Environ. Int. 2005, 31 (6), 791-798.

(27) Wu, C.; Zou, Q.; Xue, S. G.; Pan, W. S.; Huang, L.; Hartley, W.; Mo, J. Y.; Wong, M. H. The effect of silicon on iron plaque formation and arsenic accumulation in rice genotypes with different radial oxygen loss (ROL). Environ Pollut. 2016, 212, 27-33.

(10) Jia, Y.; Huang, H.; Chen, Z.; Zhu, Y. G. Arsenic uptake by rice is influenced by microbe-mediated arsenic redox changes in the rhizosphere. Environ. Sci. Technol. 2014, 48 (2), 1001-1007

(11) Stone, R. Arsenic and paddy rice: A neglected cancer risk? Science. 2008, 321 (5886), 184-185. 
(5) Seyfferth, A. L.; Sarah, M. C.; Schaefer, M. V.; Scott, F. Arsenic concentrations in paddy soil and rice and health implications for major rice-growing regions of Cambodia. Environ. Sci. Technol. 2014, 48 (9), 4699-4706.

Qu HO, Mudalige TK, Linder SW. 2015. Arsenic speciation in rice by capillary electrophoresis/inductively coupled plasma mass spectrometry: Enzyme-assisted water-phase microwave digestion. Journal of Agricultural \& Food Chemistry 63(12): 3153-3160.

Novoa-Munoz, J.C., Queijeiro, J.M.G., Blanco-Ward, D., Alvarez-Olleros, C., Garcia-Rodeja, E., Martinez-Cortizas, A., 2007. Arsenic fractionation in agricultural acid soils from NW Spain using a sequential extraction procedure. Sci. Total Environ. $378,18-22$.

. (18) Zhao, F. J.; Mcgrath, S. P.; Meharg, A. A. Arsenic as a food chain contaminant: Mechanisms of plant uptake and metabolism and mitigation strategies. Annu. Rev. Plant Biol. 2010, 61 (4), 535-59.

(32) Ma, J. F.; Yamaji, N.; Mitani, N.; Xu, X. Y.; Su, Y. H.; McGrath, S. P.; Zhao, F. J. Transporters of arsenite in rice and their role in arsenic accumulation in rice grain. P. Natl Acad. Sci. Usa. 2008, 105 (29), 9931-9935.

Meharg AA, Hartley-Whitaker J. 2002. Arsenic uptake and metabolism in arsenic resistant and non-resistant plant species. New Phytologist 154: 29-43.

Liu WJ, Zhu YG, Smith FA, Smith SE. 2004. Do phosphorus nutrition and iron plaque alter arsenate (as) uptake by rice seedlings in hydroponic culture? New Phytologist 162(2): 481-488.

[52] Abedin, M. J.; Feldmann, J.; Meharg, A. A. Uptake kinetics of arsenic species in rice plants. Plant Physiol. 2002, 128, 1120-1128.

HU Y, LI J H, ZHU Y G., HUANG Y Z, HU H Q, CHRISTIE P. Sequestration of As by iron plaque on the roots of three rice (Oryza sativa L.) cultivars in a low-P soil with or without P fertilizer [J]. Environmental Geochemistry and Health, 2005, 27: $169-176$.

Wu.C.; Peng.W.S.; Xue.S.G.; Mo.J.Y.Effects of root oxidation ability and P on As mobility and bioavailability in rice. J. Cent. South Univ. (2015) 22: 74-81 
Jiang W, Hou Q, Yang Z, Zhong C, Zheng G, Yang Z, Li J. 2014. Evaluation of potential effects of soil available phosphorus on soil arsenic availability and paddy rice inorganic arsenic content. Environmental Pollution 188: 159-165.

(20) Xu, X. Y.; McGrath, S. P.; Meharg, A. A.; Zhao, F. J. Growing Rice Aerobically Markedly Decreases Arsenic Accumulation. Environ. Sci. Technol. 2008, 42 (15), 5574-5579.

(21) Li, R. Y.; Stroud, J. L.; Ma, J. F.; McGrath, S. P.; Zhao, F. J. Mitigation of arsenic accumulation in rice with water management and silicon fertilization. Environ. Sci. Technol. 2009, 43 (10), 3778-3783.

Somenahally, A. C.; Hollister, E. B.; Wengui, Y.; Gentry, T. J.; Loeppert, R. H. Water management impacts on arsenic speciation and iron-reducing bacteria in contrasting rice-rhizosphere compartments. Environ. Sci. Technol. 2011, 45 (19), 8328-8335.

(49) Norton, G. J.; Adomako, E. E.; Deacon, C. M.; Carey, A. M.; Price, A. H.; Meharg, A. A. Effect of organic matter amendment, arsenic amendment and water management regime on rice grain arsenic species. Environ. Pollut. 2013, 177 (4), $38-47$.

(23) Takahashi, Y.; Minamikawa, R.; Hattori, K. H.; Kurishima, K.; Kihou, N.; Yuita, K. Arsenic behavior in paddy fields during the cycle of flooded and non-flooded periods. Environ. Sci. Technol. 2004, 38 (4), 1038-44.

Abedin MJ, Cresser MS, Meharg AA, Feldmann J, Cotter-Howells J. 2002b. Arsenic accumulation and metabolism in rice (Oryza sativa L.). Environmental Science \& Technology 36, 962-968.

Marin AR, Masscheleyn PH, Jr Patrick WH. 1993. Soil redox-pH stability of arsenic species and its influence on arsenic uptake by rice. Plant \& Soil 152, 245-253. Carbonell AA, Aarabi MA, Delaune RD, Gambrell RP, Jr WHP. 1998. Arsenic in wetland vegetation: Availability, phytotoxicity, uptake and effects on plant growth and nutrition. Science Of The Total Environment 217, 189-199.

Wu C, Zou Q, Xue SG, Mo JY, Pan WS, Lou LQ, Wong MH. 2015. Effects of silicon ( $\mathrm{Si}$ ) on arsenic (as) accumulation and speciation in rice (Oryza sativa L.) genotypes with different radial oxygen loss (ROL). Chemosphere 138, 447-453. 
Comis D. 1996. Aerenchyma — lifelines for living underwater. Agricultural Research 45, 4-8.

Wu C, Ye ZH, Li H, Wu SC, Deng D, Zhu YG, Wong MH. 2012. Do radial oxygen loss and external aeration affect iron plaque formation and arsenic accumulation and speciation in rice? Journal of Experimental Botany 63, 2961-2970. 